\title{
Editorial
}

\section{Tratemos a la persona y al dolor}

\author{
I. Carabaño Aguado, C. Cordero Castro
}

Servicio de Pediatría. Hospital Rey Juan Carlos. Móstoles, Madrid. España.

Siguiendo la terminología del sociólogo Vicente Verdú, la era del capitalismo de ficción estuvo marcada por el estado de bienestar ${ }^{1}$. Cualquier mínima perturbación del mismo era percibida de una forma claramente negativa. Eso nos hizo a los adultos un tanto caprichosos, pueriles, atemperados, sensibleros e intolerantes a la crítica, aunque esta fuera constructiva. No obstante, no todos los frutos del estado del bienestar fueron malos: también los hubo buenos, como la concienciación sobre el manejo del dolor. El concepto "dolor" pasaba así de ser algo inevitable e incluso vigorizante a un hecho incómodo y combatible.

Esta variación conceptual motivó la creación de las llamadas "Unidades del Dolor", que atendieron en su inicio a pacientes con dolor crónico producido por cáncer, en situación terminal o casi terminal. Estas unidades atenuadoras del malestar rápidamente cobraron interés por parte de la población general, y su ámbito se extendió al dolor crónico producido por entidades benignas pero muy molestas, como la lumbalgia mecánica refractaria a la medicación habitual.

Todo ha ido más despacio en el campo pediátrico. Hasta el año 2005, fecha de constitución del Grupo de Trabajo para Analgesia y Sedación (GTAS) de la Sociedad Española de Urgencias de Pediatría (SEUP) (www.seup.org), no se institucionaliza de forma destacada la sedoanalgesia en niños, ejecutada por pediatras. Previamente, hubo iniciativas aisladas, de mayor o menor calado social y científico, pero hasta esa fecha los pediatras españoles no tomamos una conciencia integral de que es necesario manejar el dolor de forma enérgica en los niños. De este modo, se profesionalizó el tratamiento de la percepción álgica producida por hechos tan dispares como una venopunción (si me permiten decirlo llanamente: era evidente que aquello de soplar no servía para nada), la reducción de una fractura, la sutura de una herida y un largo etcétera. De la mano de la sedoanalgesia pediátrica, el tratamiento del dolor neonatal también experimentó un auge. Hoy por hoy, no hay Unidad/ Servicio de Neonatología que se precie que no cuente con un protocolo en este sentido. De igual modo, en Atención Primaria se atiende de manera creciente el dolor.

Decía Blas de Otero aquello de "creo en el hombre"2. Tal cual vemos, instalados como estamos en la llamada era del "capitalismo funeral"3, extinta la vigencia del modelo capitalista clásico y del estado de bienestar, inmersos en un complejo entramado de deudas, paro y recortes presupuestarios, nos queda volver al hombre, al ser, a la humanización, más que nada, porque no nos queda otra cosa.

La humanización asistencial ha llegado a su momento culmen. La solidaridad hacia el paciente, superado el concepto de "cliente asistencial", despierta entre los sanitarios sentimientos de protección, de ternura, maternales, femeninos; en esen- 
cia, porque ese que tenemos enfrente y que lo pasa mal podemos ser nosotros mismos en un abrir y cerrar de ojos, si nos vemos sin trabajo, si nos sobreviene un cáncer, si nuestro hijo enferma, etc.

La sociedad está en otra cosa muy distinta a lo que opinan, desacertadamente, algunos gestores. No será mejor el centro que tenga una mejor cartera de servicios, sino el que equilibre adecuadamente el hecho de disponer de un buen catálogo de medios diagnósticos/terapéuticos con un buen modelo de trato al individuo, al yo, al enfermo.

El futuro filosófico del modelo asistencial, más allá de su sostenibilidad, pasa por una orientación correcta hacia el paciente. Este posicionamiento social unánime queda reflejado en el interés despertado por libros como Crónicas del dolor, de Melanie Thernstrom ${ }^{4}$; o de textos tan destacables como Historia cultural del dolor, de Javier Moscoso 5 . Incluso algunas performances artísticas extremas, como las de Ron Athey (http://ronatheynews. blogspot.com.es/), tienen como protagonista al sufrimiento, al hecho de padecer, al condenable y odioso penar físico. Unámonos, pues, a esta corriente, que es la nuestra y llevemos a hospitales y a centros de salud el trato humanizado y unos correctos protocolos de sedoanalgesia.

\section{BIBLIOGRAFÍA}

1. Verdú V. El estilo del mundo. La vida en el capitalismo de ficción, 1.ㄹ ed. Barcelona: Anagrama; 2006.

2. De Otero B. Ancia, 1. e ed. Madrid: Visor; 1984

3. Verdú V. El capitalismo funeral. La crisis o la Tercera Guerra Mundial, 1. ㄹ ed. Barcelona: Anagrama; 2009.

4. Thernstrom M. Crónicas del dolor, 1. a ed. Barcelona: Anagrama; 2012.

5. Moscoso J. Historia cultural del dolor, 1. ${ }^{\mathrm{a}}$ ed. Madrid: Taurus; 2011. 